\title{
Co-ordination of the sexual signalling system and the genetic basis of differentiation between populations in the brown planthopper, Nilaparvata Iugens
}

\author{
R. K. BUTLIN \\ Department of Biology, The University of Leeds, Leeds LS2 9JT, U.K.
}

\begin{abstract}
Substrate-transmitted sexual signals and female responses to synthetic male signals were analysed for three populations of brown planthopper, Nilaparvata lugens (Homoptera: Delphacidae). Mean female preferences closely match mean male signal pulse repetition frequencies (PRF) in each population, despite marked differences among populations in PRF of both male and female signals. Female response windows (the range of male signal PRFs that elicit responses) were similar in all populations and wide relative to male signal variation. The Wright-Castle-Lande method was used to estimate the number of loci affecting differences between populations in male and female sexual signals and female preferences. Estimates obtained using the Lande formulae were compared with estimates from an iterative modelfitting approach. No sex linkage was observed. The characters conformed to the expectations of additive inheritance, with directional dominance in two cases. Estimates for the number of loci involved in signal characters were low, ranging from 1.4 to 5.3. After corrections for bias in the estimation method, estimates range from 2 to 16 but are still substantially lower than the recombination index of about 25 . Estimates of the number of loci influencing female preference were unreliable. The two estimation methods gave compatible results but the iterative estimation method made better use of the data and gave clearer guidance on the support for the estimates. The results are discussed in the light of potential causes of divergence in sexual signalling systems.
\end{abstract}

Keywords: female preference, mating signal, number of genes, quantitative trait loci, sexual selection, speciation.

\section{Introduction}

Divergence in sexual signalling systems, leading to prezygotic isolation, is an important component of speciation in animals. Recent studies suggest that behavioural isolation may evolve rapidly (Kaneshiro \& Boake, 1987; Coyne \& Orr, 1989) but there is little agreement about the mechanisms underlying divergence (e.g. Butlin, 1989; Butlin \& Ritchie, 1989; Kaneshiro, 1989; Löfstedt, 1993). An understanding of the genetic basis of differences between populations or species in the components of the sexual signalling system would help to inform this debate. However, as with postzygotic isolation, the amount of information available is very limited (Coyne, 1992; Ritchie, 1992; Coyne et al., 1994).
The genetic basis of prezygotic isolation has been analysed in several species pairs without reference to the signals and responses involved (e.g. Drosophila paulistorum races, Ehrman, 1961; D. mojavensis/ arizonae, Zouros, 1981). There is some information on the inheritance of acoustic signals in a few examples (see Butlin \& Ritchie, 1989), but there are very few studies that have examined both signals and responses. The most complete case is the European corn borer moth in which pheromone blend, male antennal reception and male behavioural response are each controlled by a single major locus, on the sex chromosome in the case of the male response locus (Roelofs et al., 1987; Löfstedt et al., 1989). Comparable, but less complete, results have been obtained for other moth species (Löfstedt, 1993). Pheromonal and visual signals, and associated 
responses, have been examined in the butterflies Colias eurytheme and $C$. philodice. Female response and both types of signal are controlled by the sex chromosomes (Grula \& Taylor, 1980a,b).

Several hypotheses concerning signal system divergence during speciation can be tested with knowledge of the genetic architecture of the divergent characters. Major gene differences might be more likely under natural selection than under genetic drift (Templeton, 1981) and dominance might indicate the direction of evolution. The genetic coupling hypothesis predicts that signals and responses will have common genetic control (Butlin \& Ritchie, 1989). It has been suggested that the sex chromosomes might play a disproportionate role in divergence because of the exposure of recessive mutations to selection in males (Ewing, 1969; Charlesworth et al., 1987; but see Hurst \& Pomiankowski, 1991). However, the data available at present are insufficient to allow any generalizations to be made about these predictions.

It is clearly important to consider both signals and responses, not only because of the possibility of genetic coupling or tight linkage (Trickett \& Butlin, 1994) and the opportunity to compare the numbers of loci involved, but also because competing theories of signalling system divergence make different predictions about signal-receiver co-ordination. Models of divergence by intersexual selection, whether Fisherian, 'good genes', or 'sensory exploitation' (Kirkpatrick \& Ryan, 1991), predict that divergent populations will show different balances between sexual and other components of selection. Thus they predict that, if signal characters differ among populations, mean preferences cannot correspond to mean signal values in all populations. In guppies, Poecilia reticulata, for example, both male coloration and female preferences vary among populations, with females preferring males more brightly coloured than the average in some, but not all populations (Houde \& Endler, 1990). By contrast, models of divergence that emphasize co-ordination between signal and receiver, and adaptation to environmental conditions (Paterson, 1985), predict that mean preference and mean signal will always be closely matched. The few other species in which geographical variation in both signals and preferences has been studied generally show close matching (e.g. Acris crepitans, Nevo \& Capranica, 1985; Agrotis segetum, Tòth et al., 1992; Chrysoperla plorabunda, Wells \& Henry, 1992) unlike Poecilia reticulata (Houde \& Endler, 1990).

Here I report an analysis of male signals, female response signals and female preferences in the brown planthopper, Nilaparvata lugens (Stål) (Homoptera: Delphacidae). Three populations, known to be divergent for male signal characteristics, have been studied. The Wright-Castle-Lande method (Lande, 1981) has been used to estimate the minimum number of loci influencing each of these characters in crosses between two pairs of populations. This well-known method is based on a comparison of the difference between population means for a quantitative character with the additional variance in the character in segregating generations. It has serious shortcomings (Zeng et al., 1990), but allowances can be made for the major sources of bias (Zeng, 1992) and it remains the only approach available in the absence of an extensive suite of marker loci.

The formulae given by Lande (1981) for the effective number of loci influencing a character, and for the standard error of the estimate, can produce results that are difficult to interpret. Estimates are typically noninteger values and they may be negative. Standard errors may be large, are strongly influenced by variance estimates based on small sample sizes, and they give the false impression that confidence intervals are symmetrical about the estimate. The least squares approach introduced by Cockerham (1986) makes better use of the data. The method suggested here is similar, comparing the likelihood of the full data set for specified integer numbers of loci after iterative optimization of the parameters in the simple underlying model of Wright (1968).

The brown planthopper is a major pest of rice in India, South-east Asia and parts of Australia. In addition to rice-feeding populations, the species is also found on another grass, Leersia hexandra, which often grows in close proximity to rice crops. Populations feeding on Leersia may represent a separate species, despite the lack of any known morphological difference (Claridge et al., 1985b, 1988; Jones et al., 1994). Male brown planthoppers produce substrate-transmitted mating signals to which receptive females respond with signals of a distinct pattern. The male signals consist of three phases of which the second is an $\approx 2$ s burst of heavily damped pulses with a pulse repetition frequency (PRF) of 50-120 pulses per second (Fig. 1). Only this central phase appears to be required to elicit female response (Butlin, 1993). Female responses consist of prolonged trains of pulses with much lower PRF (5-25 pulses per second) (Fig. 1). The PRFs of both sexes vary between geographically isolated populations in both rice- and Leersia-feeding forms, and between these forms in the same geographical area 
(a)

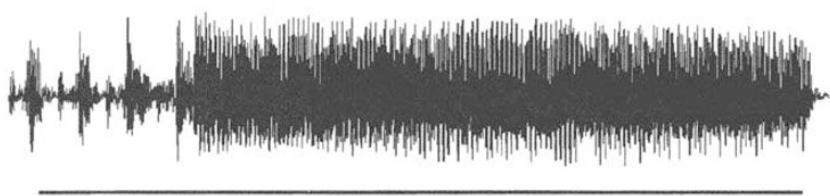

(b)

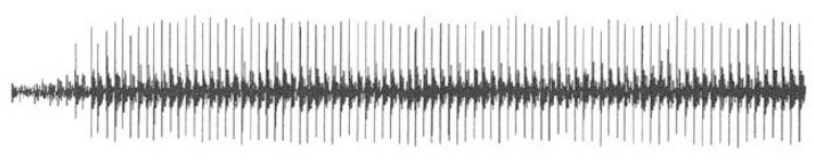

Fig. 1 Oscillograms of examples of male (a) and female (b) substrate-transmitted signals from the BR population. Bar is $2 \mathrm{~s}$ in each case.

(Claridge et al., 1985a,b, 1988). There is good evidence that the PRF of male song is important in female mate choice (Claridge et al., 1984).

Butlin (1993) developed a method for measuring the mean preference of individual females, and the range of signals to which they will respond, by playback of synthesized male signals. This study showed that genetic variation within populations is negligible for male PRF, female PRF and mean female preference but that genetic variation does exist for the range of acceptable signals, called the preference 'window'.

Given this background information, brown planthopper is a good candidate for the comparison of signal and preference variation and for the estimation of numbers of loci influencing components of the sexual signalling system. Two comparisons have been made: between Indian and Australian ricefeeding populations (among the most divergent of the rice-feeding form), and between a rice-feeding and a Leersia-feeding population.

\section{Materials and method}

\section{Stocks}

Three stocks were used: BR - derived from a collection made at Dhanbad, Bihar, India in 1989 from cultivated rice (the stock used by Butlin, 1993); AR - derived from a collection made near Ayr, Queensland, Australia in 1990 from cultivated rice; and JL derived from a collection made at Bogor, Java, Indonesia in 1990 from Leersia hexandra. All collections were of at least 20 adult individuals. The BR stock was maintained on the rice variety $\mathrm{TN} 1$ as a set of 10 isofemale lines, the AR stock was maintained in bulk on rice variety Delta, and the JL stock was maintained in bulk on Leersia hexandra. Generation time is four to six weeks and the experimental crosses were made in 1990 and 1991.

\section{Crosses}

Virgins were produced by separating individuals as nymphs. $\quad \mathrm{BR} \times \mathrm{JL}$ and $\mathrm{JL} \times \mathrm{BR}$ crosses (female parent first in all cases, BR-JL refers to both reciprocals) were made, and the $F_{1}$ offspring were reared, with both host plants available. The $F_{1}$ adults were allowed to mate and oviposit in these conditions and newly emerged nymphs were then moved onto either TN1 or Leersia plants at 30 nymphs per plant.

$\mathrm{AR} \times \mathrm{BR}$ and $\mathrm{BR} \times \mathrm{AR}$ crosses were made in the same way except that parents were mated, and the $F_{1}$ and $F_{2}$ offspring reared, on Delta only because both parental stocks perform well on this variety.

\section{Signal and preference measurement}

The methods for signal recording and analysis have been described in detail elsewhere (Butlin, 1993). These methods were followed exactly except that males were recorded on only one occasion.

Similarly, the methods for assessing female preferences were identical to those used previously (Butlin, 1993) except that a different set of synthesized signals was used. This change was necessary to extend the range of PRFs covered. The signals used had PRFs of 40, 52, 64, 76, 88, 100, 112, 124 and 136 pulses per second. Briefly, these were played in rising or falling sequence, three times each on separate days, to individual sexually mature females. The signal at which the female started to produce response song was recorded in each case. Average values for these responses to the rising and falling sequences are taken as measures of the lower and upper bounds, respectively, of the female's preference. The female's mean preference is the midpoint of these bounds and her preference 'window' is the interval between them.

\section{Analysis}

Data are available for the three parental stocks, the $\mathrm{F}_{1} \mathrm{~s}$, and the $\mathrm{F}_{2} \mathrm{~s}$. Estimates of the minimum number of loci have been made for signals and preferences in the BR-JL combination but for male signals only in the BR-AR combination because sample sizes for 
preferences were too small and female signals too similar in this cross. Only female mean preference is considered because populations were not found to differ in preference window. These behavioural data differ from the morphometric data more commonly used in this type of analysis in that there is substantial within-individual variability (Butlin, 1993). Therefore, when using the Lande (1981) method, the among-individual component of variance was estimated by hierarchical analysis of variance for each character in each stock or cross. This analysis also estimated variation among offspring of individual pairs of parents, and among replicate plants (cf. Butlin, 1993). In no case was either of these components of variance statistically significant $(P<0.05)$. Least-square means for individuals, derived from this analysis of variance, were used in the iterative model-fitting approach. On an untransformed scale there is some dependence of the variance on the mean, particularly for female PRF. Therefore both untransformed data and data transformed to logarithms have been analysed.

The estimates of the number of loci influencing a character, $m$, and their standard errors, were obtained using formulae $4 \mathrm{~b}$ and $8 \mathrm{~b}$ from Lande (1981). However, these were modified to use only data from the parental and $F_{2}$ generations where $F_{1}$ sample sizes were small. The usual reason for using $F_{1}$ as well as parental data to estimate environ- mental variance (plus genetic variance within parental stocks where applicable) is that this may be greater in the 'unbalanced' hybrid genotype. Because hybrid genotypes also occur in the $F_{2}$, a weighted mean of the $F_{1}$ and parental variances may give the best estimate of environmental variance in the $F_{2}$ (Lande, 1981). Neither the data available here (Table 1) nor previous analyses of hybrids (Claridge et al., 1985a, 1988) provide evidence that $\mathrm{F}_{1}$ variance exceeds parental variance for the characters analysed here, with the possible exception of mean preference (see below).

The alternative approach operates as follows. On the additive model, the $F_{1}$ and $F_{2}$ means are simply the mid-point between the parental means. The parental and $F_{1}$ variances are all estimates of the environmental variance, $V_{\mathrm{e}}$ (possibly including genetic variation within lines, Lande, 1981). The $F_{2}$ variance is the sum of the environmental variance and the variance attributable to segregation $\left(V_{\mathrm{s}}\right)$, which is a function of the difference between the parental means (P1 and $P 2)$ and the effective number of loci $(m)$ :

$V_{\mathrm{F} 2}=V_{\mathrm{e}}+V_{\mathrm{s}}=V_{\mathrm{e}}+\left[(P 1-P 2)^{2} / 8 m\right]$.

Thus, for a given value of $m$ it is possible to vary just three parameters, $P 1, P 2$ and $V_{\mathrm{e}}$, to find the combination that maximizes the likelihood of the observed data. This can be repeated for values of $m$

Table 1 Summary of observations on sexual signals in Nilaparvata lugens

\begin{tabular}{|c|c|c|c|c|c|c|c|c|c|c|c|}
\hline Character & & BR & $\mathrm{JL}$ & $\mathrm{AR}$ & $\begin{array}{c}\mathrm{BR} \times \mathrm{JL} \\
\mathrm{F}_{1}\end{array}$ & $\begin{array}{c}\mathrm{JL} \times \mathrm{BR} \\
\mathrm{F}_{1}\end{array}$ & $\begin{array}{c}\mathrm{AR} \times \mathrm{BR} \\
\mathrm{F}_{1}\end{array}$ & $\begin{array}{c}\mathrm{BR} \times \mathrm{JL} \\
\mathrm{F}_{2}\end{array}$ & $\begin{array}{c}\mathrm{JL} \times \mathrm{BR} \\
\mathrm{F}_{2}\end{array}$ & $\begin{array}{c}\mathrm{BR} \times \mathrm{AR} \\
\mathrm{F}_{2}\end{array}$ & $\begin{array}{c}\mathrm{AR} \times \mathrm{BR} \\
\mathrm{F}_{2}\end{array}$ \\
\hline \multirow[t]{3}{*}{ Male PRF } & $x$ & 80.39 & 100.00 & 94.61 & 79.00 & 78.45 & 87.85 & 88.86 & 84.90 & 90.07 & 86.93 \\
\hline & $s^{2}$ & 28.44 & 36.49 & 16.31 & 33.60 & 21.45 & 14.15 & 26.35 & 34.27 & 24.01 & 50.54 \\
\hline & $n$ & 17 & 24 & 10 & 4 & 2 & 2 & 80 & 46 & 24 & 36 \\
\hline \multirow[t]{3}{*}{ Female PRF } & $x$ & 20.94 & 6.25 & 24.47 & 13.58 & 12.68 & & 13.23 & 14.15 & & \\
\hline & $s^{2}$ & 1.779 & 0.3604 & 2.707 & 3.174 & 0.189 & & 8.452 & 4.533 & & \\
\hline & $n$ & 23 & 18 & 4 & 6 & 4 & & 48 & 27 & & \\
\hline \multirow{3}{*}{ Lower preference limit } & $x$ & 74.44 & 86.72 & 72.25 & 83.00 & 76.80 & & 75.65 & 83.87 & & \\
\hline & $s^{2}$ & 53.13 & 149.7 & 589.2 & 294.0 & 19.20 & & 187.4 & 144.5 & & \\
\hline & $n$ & 18 & 10 & 5 & 6 & 5 & & 31 & 19 & & \\
\hline \multirow{3}{*}{ Upper preference limit } & $x$ & 94.61 & 110.1 & 108.9 & 112.0 & 94.00 & & 103.7 & 103.2 & & \\
\hline & $s^{2}$ & 205.5 & 88.67 & 32.00 & 136.0 & 5.33 & & 83.57 & 82.34 & & \\
\hline & $n$ & 18 & 10 & 4 & 6 & 4 & & 31 & 19 & & \\
\hline \multirow[t]{3}{*}{ Mean preference } & $x$ & 82.81 & 97.16 & 90.00 & 97.50 & 91.18 & & 89.44 & 92.63 & & \\
\hline & $s^{2}$ & 47.76 & 56.67 & 165.1 & 143.5 & 11.67 & & 42.66 & 42.92 & & \\
\hline & $n$ & 18 & 10 & 4 & 6 & 4 & & 31 & 19 & & \\
\hline \multirow[t]{3}{*}{ Preference window } & $x$ & 19.65 & 26.10 & 40.57 & 29.00 & 17.00 & & 29.55 & 20.16 & & \\
\hline & $s^{2}$ & 326.3 & 250.1 & 576.5 & 286.0 & 14.67 & & 373.7 & 281.9 & & \\
\hline & $n$ & 18 & 10 & 4 & 6 & 4 & & 31 & 19 & & \\
\hline
\end{tabular}

$x$, mean value of PRF in pulses per second; $s^{2}$, among-individual variance; $n$, degrees of freedom for the among-individual variance. 
from 1 to the recombination index, the maximum estimate possible. Comparison of the likelihoods will yield the best estimate of $m$ and its support limits (ranges of estimates with log-likelihoods less than two units below the maximum, Edwards, 1972).

This procedure was implemented using the FITNONLINEAR procedure of GENSTAT 5 (GENSTAT, 1987) which uses a modified Newton algorithm to search the parameter space, with explicit calculation of log-likelihoods. Starting parameter values were the observed means and variances, and variance estimates were constrained to be positive.

Two more complex models were also fitted. The first allowed the parental variances to differ and assumed that the $F_{1}$ variance was the mean of the parental variances. This gives four parameters: $V_{\mathrm{P} 1}$, $V_{\mathrm{P} 2}, P 1$ and $P 2$. The second alternative model allowed for directional dominance by adding the parameter $h(0$ - complete dominance of $P 1,1$ complete dominance of $P 2,0.5$ - no dominance) and modifying the relationships between means and variances as specified by Wright (1968). This model also has four parameters: $V_{\mathrm{e}}, P 1, P 2$ and $h$. Because each of these models has one parameter more than the simple model, they are expected to improve the likelihood of the data. They were considered significantly better than the simple model if twice the improvement in the log-likelihood exceeded $\chi_{1}^{2}$ (Edwards, 1972).

\section{Results}

Both the JL and AR populations differed significantly $(P<0.01)$ from the BR population for male and female signal PRFs, as expected from previous observations (Claridge et al., 1985a, 1988) (Table 1). The JL and BR populations also differed significantly $(P<0.01)$ in the upper and lower female preference limits and the mean female preference. Mean female preference was co-ordinated with mean male signal in each of these populations, differing by less than the male signal standard deviation in each case. These two populations did not differ in the width of the preference window. The preference windows overlap, which is consistent with the incomplete assortative mating observed between populations with similar divergence in male PRF (Claridge et al., 1988). Despite the smaller sample sizes, this pattern is repeated for female preference measurements in the AR population.

The BR preference results are closely similar to those of Butlin (1993), despite the change in range of synthesized signal PRFs. This repeatability, and the clear-cut difference between populations, demonstrates that the playback technique provides satisfactory measures of the characteristics of female preference.

Previous studies of $\mathrm{F}_{1}$ hybrids (Claridge et al., 1985a, 1988) have not given any evidence for either sex linkage or directional dominance. The small numbers of $F_{1}$ individuals studied here did not differ between reciprocal crosses for any character, confirming the absence of sex linkage. The $F_{1}$ mean was intermediate between the parental means in all cases except male PRF for the BR-JL crosses, where it does not differ significantly from the BR mean (Table 1). In this case the $F_{2}$ mean is intermediate between the BR mean and the mid-point of the parental means, confirming directional dominance of $B R$ alleles. Other $F_{2}$ means are closely similar to $F_{1}$ means, as expected on an additive model, with the possible exception of female PRF in the BR-JL cross (see below).

Survival of $F_{2}$ individuals was high in BR-AR crosses, averaging 67 per cent. In BR-JL crosses, survival of the $F_{2}$ on TN1 averaged 79 per cent but no individuals survived on Leersia hexandra out of nine replicates of 30 nymphs each. It is possible that mortality on rice was biased towards individuals with more JL alleles. However, this would have produced $\mathrm{F}_{2}$ means closer than expected to the BR parent, which was not observed, even in the case of male PRF where the complete dominance suggested by the $F_{1}$ would have produced a lower mean (i.e. closer to BR) than that actually observed in the $F_{2}$.

Estimates of $m$, from both methods, are given in Table 2 and will be discussed below. A negative estimate using the Lande method occurred for female mean preference where the $F_{2}$ variance is less than the combined estimate of variance from the parents and $F_{1}$. Since this implies that the variance attributable to segregation is small, it is interpreted as an indefinitely large estimate for the number of loci.

\section{Discussion}

The comparison between signal and preference characteristics of the divergent populations from rice and Leersia (BR and JL) shows maintenance of co-ordination, rather than the pattern expected from different balances between sexual and other components of selection. Indeed, if divergence in male signals were the result of intersexual selection, one would expect preferences to differ more between populations than do signals. In fact, if anything the reverse is true: there is no evidence that signal diver- 
gence has been driven by diverging female preferences.

The two methods for the estimation of the effective numbers of loci influencing signals and preferences gave comparable results. However, the model-fitting approach allowed utilization of all the data without small sample sizes for some generations, in this case the $F_{1}$, inflating the estimated standard error. The support limits give a much more meaningful idea of the range of possible values than the standard errors calculated by Lande's method, especially because they emphasize the asymmetry about the best estimate. This is expected because the estimate of $m$ becomes large as the segregation variance approaches zero. The model-fitting approach identifies the directional dominance in the case of male PRF in the BR-JL cross and estimates $h$ as $0.103 \pm 0.141(0.123 \pm 0.146$ on the log scale $)$, indicating nearly complete dominance of the low PRF of $\mathrm{BR}$ as expected. Considering female PRF in this cross, the outcome differs between scales. On the untransformed scale, the parental variances differ but the character appears additive. On the logarithmic scale, which might be expected to be preferable for a frequency character over such a wide range, the parental variances are more nearly equal but there is evidence for directional dominance of the $\mathrm{BR}$ alleles, in this case for higher PRF $(h=0.354 \pm 0.033)$.

Male and female signal pulse repetition frequencies provide consistent estimates of the effective number of loci, $m$, of 4 or 5 for the rice- and Leersia-feeding populations (BR and JL), and about 1.5 for male PRF in the rice-feeding populations from India and Australia (BR and AR). The two pairs of populations differ by similar amounts for male PRF (about three phenotypic standard deviations) but much less than for female PRF in the BR-JL pair (about 15 phenotypic standard deviations). This suggests that allelic substitutions between BR and JL have smaller effects on male PRF than substitutions between $A R$ and $B R$, or substitutions influencing female PRF. It is very unlikely that the same loci influence both the male and female characters as there is no correlation among populations between male and female PRF either here or in other populations (Claridge et al., 1985a, 1988).

As expected, the character with the greatest phenotypic difference between the parents (female PRF in the BR-JL pair) provides the most reliable estimate of $m$. Although there are significant differences between populations for the female preference characters (except 'window'), the differences are not great relative to the phenotypic variation (less than two phenotypic standard deviations). Together with the $F_{2}$ sample size of only 50 , this has produced unsatisfactory estimates of $m$.

Four sources of bias affect the estimate $m$ of the number of loci influencing a quantitative character (Zeng et al., 1990; Zeng, 1992): (1) lack of fixation of increasing alleles in the high population and decreasing alleles in the low population; (2) differences in allelic effects among loci; (3) linkage; and (4) departures from additivity. All of these biases cause $m$ to underestimate the true number of loci. The effects of (1) are generally small by comparison with the other sources of bias, especially for highly divergent populations (Lande, 1981; Zeng et al., 1990). Departures from additivity (4) can generally be dealt with by choice of an appropriate scale. In the present case male PRF in the BR-JL cross departs from additivity on both scales and, because the $F_{1}$ mean is effectively equal to the $B R$ mean, no change in scale would remove this problem. Wright (1968) provides a correction for dominance (eqn 15.11 , p. 384) which for complete dominance is an increase in the estimate $m$ by a factor of 1.5 . This can be applied to the Lande estimates in Table 2. It is already included in the fitted models incorporating dominance.

Zeng (1992) provides corrections for unequal allelic effects (2) and linkage (3). The effect of linkage depends on the number of chromosomes and the frequency of chiasmata. Nilaparvata lugens has a haploid complement of 15 chromosomes (Den Hollander, 1982). Assuming a genetic length of 0.5 Morgans for each chromosome, the mean frequency of recombination, $r$ (Zeng, 1992; eqn 5) is estimated to be 0.48 . The influence of variation in allelic effects among loci is more difficult to deal with, partly because it is very difficult to measure and partly because the inclusion of loci with ever smaller effects can continue indefinitely. If interest is restricted to the number of loci that account for the bulk of the difference between two populations, then Zeng (1992) has shown that this may be largely independent of the distribution in allelic effects especially where this is leptokurtic, as seems likely to be the case (i.e. the parameter $z$ [Zeng, 1992; eqn 6] is greater than 2).

These corrections can be applied to the estimates of $m$ in Table 2 using eqn 4 of Zeng (1992), together with Wright's correction for dominance where appropriate. They result in increases in estimates from 1.5 to two loci, and five to 11 loci (without dominance) or 16 loci (with complete dominance and using the Lande estimate). These values remain 
substantially smaller than the estimated recombination index of 25 and suggest that the signals are influenced by a limited number of loci.

No comparable analysis has been conducted for sexual signal or preference characters, except for the study of female songs in a related planthopper by De Winter (1992) which indicated that at least six loci influence PRF. Henry (1985) suggested that the number of loci influencing substrate-transmitted signals in lacewings was low, on the basis of the recovery of parental-like signals in the $F_{2}$ generation of a cross between populations whose signals differed in many ways. The differences in song rhythm between Drosophila melanogaster and $D$. simulans are caused by mutations at the per locus (Kyriacou \& Hall, 1986; Peixoto et al., 1992). A marker analysis of song characters in $D$. virilis and $D$. lummei demonstrated polygenic inheritance (Hoikkala \& Lumme, 1984) whereas a comparable analysis of cuticular hydrocarbons in $D$. simulans and $D$. sechellia suggests involvement of a small number of loci (Coyne et al., 1994). Other studies of Drosophila species and various Orthoptera also suggest polygenic inheritance with little directional dominance but sex linkage in some cases (see Ewing, 1989). However, these studies have generally not made systematic analyses of the variance in segregating generations. Female preferences have not been studied. Clearly, it is not yet possible to generalize about the inheritance of signal system components.

A small number of loci may indicate divergence under selection, rather than by drift, because the larger the effect of an individual substitution the less likely it is to be selectively neutral. The strong directional dominance in the case of BR male PRF may indicate that low PRF is the derived character in this case. However, the maximum contribution of a single locus to male PRF (less than or equal to $\left(\mu_{1}-\mu_{2}\right) / \sqrt{ } m$, Wright, 1968) is in the region of 10 pulses per second for BR-AR or six for BR-JL, which is much less than the width of the female preference window. This implies that selection resulting from female preference would be weak for each allele substitution. For female signals, the maximum contribution is about five pulses per second for BR-JL. Male response to female signals appears to be relatively indiscriminate in Nilaparvata (Butlin, 1993) suggesting that selection on female signals arising from mate choice will also be weak, although selective phonotaxis by males is strong in a related genus (Ribautodelphax, De Winter \& Rollenhagen, 1990).

The different directions of change for male and female PRF between host plants in these samples, and the general lack of correlation across populations in previous work (Claridge et al., 1985a,b, 1988), argues against selection resulting from simple physical features of the host plants. Other selection pressures may be involved, of course, such as interactions with other species using the same signalling channel or pressure from acoustically orienting predators.

Molecular data (Jones et al., 1994) suggest that rice- and Leersia-associated populations in Asia are more closely related to each other than either is to rice-associated populations in Australia. This adds to the case for involvement of selection in the divergence between $\mathrm{BR}$ and $\mathrm{JL}$ in both male and female PRF, because greater differentiation has apparently arisen in a shorter period of time. The suggestion that $\mathrm{BR}$ male signals are the derived

Table 2 Estimates of the effective number of loci $(m)$ influencing each sexual signal character in Nilaparvata lugens

\begin{tabular}{llcc}
\hline Cross & Character & $\begin{array}{c}\text { Lande estimate } \\
\pm \text { SE }\end{array}$ & $\begin{array}{c}\text { Maximum likelihood } \\
\text { estimate } \\
\text { (support limits) }\end{array}$ \\
\hline BR-AR & Male PRF & $1.44 \pm 0.67$ & $1(1-10)$ \\
BR-AR & Log (Male PRF) & $1.58 \pm 0.84$ & $1(1-\infty)$ \\
BR-JL & Male PRF & $3.30 \pm 1.78$ & $5(2-\infty)^{\mathrm{d}}$ \\
BR-JL & Log (Male PRF) & $4.36 \pm 3.01$ & $4(2-\infty)^{\mathrm{d}}$ \\
BR-JL & Female PRF & $4.52 \pm 0.79$ & $4(3-5)^{\mathrm{v}}$ \\
BR-JL & Log (Female PRF) & $5.30 \pm 0.93$ & $5(4-6)^{\mathrm{d}}$ \\
BR-JL & Female Mean Preference & $\infty$ & $\infty(1-\infty)$ \\
BR-JL & Log (Female Mean Preference) & $3.3 \pm 10.9$ & $\infty(1-\infty)$ \\
\hline
\end{tabular}

d - model including dominance; ${ }^{\mathrm{v}}$ - model including different parental variances. 
form is also consistent with phylogenetic information. Related species in the genus Nilaparvata, $N$. bakeri and $N$. muiri, both feed on Leersia (Claridge \& Morgan, 1987) implying that rice-feeding forms of $N$. lugens are derived from Leersia-feeding ancestors.

Signal and preference divergence in allopatric populations can be caused by three broad categories of process: (1) sexual selection, by either the Fisherian, 'good genes', or sensory exploitation mechanisms; (2) other forms of selection linked to the physical or biological environment; or (3) genetic drift. The data presented here for signal and preference divergence in brown planthopper are not consistent with sexual selection. Drift is the most likely explanation although some features of the comparison between the rice- and Leersia-feeding populations suggest the involvement of natural selection.

\section{Acknowledgements}

I am very grateful to M. F. Claridge and J. C. Morgan for practical help and advice, to Mike Ritchie and Rachel Neems for comments on the manuscript, and to Richard Nichols for statistical advice. The research was supported by the N.E.R.C. and the Royal Society. Planthoppers were imported and maintained under licence from the Ministry of Agriculture, Fisheries and Food.

\section{References}

BUTLIN, R. K. 1989. Reinforcement of premating isolation. In: Otte, D. \& Endler, J. A. (eds) Speciation and its Consequences, pp. 158-179. Sinauer Associates, Sunderland, MA.

BUTLIN, R. K. 1993. The variability of mating signals and preferences in the brown planthopper, Nilaparvata lugens. J. Insect Behav., 6, 125-140.

BUTLIN, R. K. AND RITCHIE, M. G. 1989. Genetic coupling in mate recognition systems: what is the evidence? Biol. J. Linn. Soc., 37, 237-246.

CHARLESWORTH, B., COYNE, J. A. AND BARTON, N. H. 1987. The relative rates of evolution of the sex chromosomes and autosomes. Am. Nat., 130, 113-146.

CLARIDGE, M. F. AND MORGAN, J. C. 1987. The brown planthopper, Nilaparvata lugens (Stål), and some related species: a biotaxonomic approach. In: Wilson, M. R. and Nault, L. R. (eds) Proceedings of the Second International Workshop on Leafhoppers and Planthoppers of Economic Importance, pp. 19-32. Commonwealth Institute of Entomology, London.

CLARIDGE, M. F., DEN HOLLANDER, J. AND MORGAN, J. C. 1984. Specificity of acoustic signals and mate choice in the brown planthopper Nilaparvata lugens. Entomologia exp. appl., 35, 221-226.

ClARIDGE, M. F., DEN HOLLANDER, J. AND MORGAN, J. C. 1985a. Variation in courtship signals and hybridization between geographically definable populations of the rice brown planthopper, Nilaparvata lugens (Stål). Biol. J. Linn. Soc., 24, 35-49.

CLARIDGE, M. F., DEN HOLlANDER, J. AND MORGAN, J. C. 1985b. The status of weed-associated populations of the brown planthopper, Nilaparvata lugens (Stål) - host race or biological species? Zool. J. Linn. Soc., 84, 77-90.

CLARIDGE, M. F., DEN HOLLANDER, J. AND MORGAN, J. C. 1988. Variation in hostplant relations and courtship signals of weed-associated populations of the brown planthopper, Nilaparvata lugens (Stål), from Australia and Asia: a test of the recognition species concept. Biol. J. Linn. Soc., 35, 79-93.

COCKeRHAM, C. c. 1986. Modifications in estimating the number of genes for a quantitative character. Genetics, 114, 659-664.

COYNE, J. A. 1992. Genetics and speciation. Nature, 355, 511-515.

COYNE, J. A. AND ORR, H. A. 1989. Patterns of speciation in Drosophila. Evolution, 43, 362-381.

COYNE, J. A., CRITTENDEN, A. P. AND MAH, K. 1994. Genetics of a pheromonal difference contributing to reproductive isolation in Drosophila. Science, 265, 1461-1464.

DEN HOLLANDER, J. 1982. The chromosomes of Nilaparvata lugens (Stål) and some other Auchenorrhyncha. Cytologia, 47, 227-236.

DE WINTER, A. J. 1992. The genetic basis and evolution of acoustic mate recognition signals in a Ribautodelphax planthopper (Homoptera, Delphacidae): 1. The female call. J. Evol. Biol., 5, 249-265.

DE WINTER, A. J. AND ROLLENHAGEN, T. 1990. The importance of male and female behaviour for reproductive isolation in Ribautodelphax planthoppers (Homoptera: Delphacidae). Biol. J. Linn. Soc., 40, 191-206.

EDWARDS, A. W. F. 1972. Likelihood. Cambridge University Press, Cambridge.

EHRMAN, L. 1961. The genetics of sexual isolation in Drosophila paulistorum. Genetics, 46, 1025-1038.

EWING, A. W. 1969. The genetic basis of sound production in Drosophila pseudoobscura and D. persimilis. Anim. Behav., 17, 555-560.

EWING, A. w. 1989. Arthropod Bioacoustics. Edinburgh University Press, Edinburgh.

genstat 1987. genstat 5 Reference Manual. Clarendon Press, Oxford.

GRULA, J. W. AND TAYLOR, O. R., Jr. 1980a. Some characteristics of hybrids derived from the sulfur butterflies, Colias eurytheme and C. philodice: phenotypic effects of the X-chromosome. Evolution, 34, 673-687.

GRULA, J. W. AND TAYLOR, O. R. 1980b. The effect of X chromosome inheritance on mate-selection behavior in sulfur butterflies Colias eurytheme and C. philodice. Evolution, 34, 688-695.

HENRY, C. S. 1985. Sibling species, call differences and 
speciation in green lacewings (Neuroptera: Chrysopidae: Chrysoperla). Evolution, 39, 965-984.

HOIKKALA, A. AND LUMME, J. 1984. Genetic control of the difference in male courtship sound between Drosophila virilis and D. lummei. Behav. Genet., 14, 257-268.

HOUDE, A. E. AND ENDLER, J. A. 1990. Correlated evolution of female mating preferences and male color patterns in the guppy Poecilia reticulata. Science, 248, 1405-1408.

HURST, L. D. AND POMIANKowsKI, A. 1991. Causes of sex ratio bias may account for unisexual sterility in hybrids: a new explanation of Haldane's rule and related phenomena. Genetics, 128, 841-858.

JONES, P., GACESA, P. AND BUTLIN, R. K. 1994. A molecular approach to planthopper systematics. In: Drosopoulos, S., Petrakis, P. V., Claridge, M. F. \& de Vrijer, P. W. F. (eds) Proceedings of the 8th Auchenorrhyncha Congress, pp. 7-9. Delphi, Greece.

KANESHIRO, K. Y. 1989. The dynamics of sexual selection and founder effects in species formation. In: Giddings, L. V., Kaneshiro, K. Y. \& Anderson, W. W. (eds) Genetics, Speciation and the Founder Principle, pp. 279-296. Oxford University Press, New York.

KANESHIRO, K. Y. AND BOAKE, C. R. B. 1987. Sexual selection and speciation: issues raised by Hawaiian Drosophila. Trends Ecol. Evol., 2, 207-212.

KIRKPATRICK, M. AND RYAN, M. J. 1991. The evolution of mating preferences and the paradox of the lek. Nature, 350, 33-38.

KYRIACOU, C. P. AND HALL, J. C. 1986. Interspecific genetic control of courtship song production and reception in Drosophila. Science, 232, 494-497.

LANDE, R. 1981. The minimum number of genes contributing to quantitative variation between and within populations. Genetics, 99, 541-553.

LÖFSTEDT, C. 1993. Moth pheromone genetics and evolution. Phil. Trans. R. Soc. B, 340, 167-177.

LÖFSTEDT, C., HANSSON, B. S., ROELOFS, W. L. AND BENGTSsON, B. O. 1989. No linkage between genes controlling female pheromone production and male pheromone response in the European corn borer, Ostrinia nubilalis Hübner (Lepidoptera: Pyralidae). Genetics, 123, 553-556.

NEVO, E. AND CAPRANICA, R. R. 1985. Evolutionary origin of ethological reproductive isolation in cricket frogs, Acris. Evol. Biol., 19, 147-214.
PATERSON, H. E. H. 1985. The recognition concept of species. In: Vrba, E. S. (ed.) Species and Speciation, pp. 21-29. Transvaal Museum, Pretoria.

PEIXOTO, A. A., COSTA, R., WHEELER, D. A., HALL, J. C. AND KYRIACOU, C. P. 1992. Evolution of the threonineglycine repeat region of the period gene in the melanogaster species subgroup of Drosophila. J. Mol. Evol., 35, 411-419.

RITCHIE, M. G. 1992. Setbacks in the search for mate preference genes. Trends Ecol. Evol., 7, 328-329.

ROELOFS, W., GLOVER, T., TANG, X., SRENG, I., ROBBins, P., ECKENRODE, C., ET AL. 1987. Sex pheromone production and perception in European corn borer moths is determined by both autosomal and sex-linked genes. Proc. Natl. Acad. Sci. U.S.A., 84, 7585-7589.

TEMPLETON, A. R. 1981. Mechanisms of speciation - a population genetic approach. Ann. Rev. Ecol. Syst., 12, 23-48.

TÒTH, M., LÖFSTEDT, C., BLAIR, B. W., CABELLO, T., FARAG, A. I., HANSSON, B. S. ET AL. 1992. Attraction of male turnip moths Agrotis segetum (Lepidoptera: Noctuidae) to sex pheromone components and their mixtures at 11 sites in Europe, Asia, and Africa. J. Chem. Ecol., 18, 1337-1347.

TRICKETT, A. J. AND BUTLIN R, K. 1994. Recombination suppressors and the evolution of new species. Heredity, 73, 339-345.

WELLS, M. M. AND HENRY, c. s. 1992. The role of courtship songs in reproductive isolation among populations of green lacewings of the genus Chrysoperla (Neuroptera: Chrysopidae). Evolution, 46, 31-42.

WRIGHT, s. 1968. Evolution and the Genetics of Populations, vol. 1, Genetic and Biometric Foundations. University of Chicago Press, Chicago.

zENG, Z.-B. 1992. Correcting the bias of Wright's estimates of the number of genes affecting a quantitative character: a further improved method. Genetics, 131, 987-1001.

ZENG, Z.-B., HOULE, D. AND COCKERHAM, C. C. 1990 . How informative is Wright's estimator of the number of genes affecting a quantitative character? Genetics, 126, 235-247.

zouros, E. 1981. The chromosomal basis of sexual isolation in two sibling species of Drosophila: $D$. arizonensis and D. mojavensis. Genetics, 97, 703-718. 